\title{
Impact of dyslipidemic components of metabolic syndrome, adiponectin levels, and anti-diabetes medications on malondialdehyde-modified low-density lipoprotein levels in statin-treated diabetes patients with coronary artery disease
}

Morihiro Matsuda ${ }^{1,2,3^{*}}$, Ritsu Tamura', Kotaro Kanno ${ }^{1}$, Takatsugu Segawa ${ }^{1}$, Haruyuki Kinoshita', Orie Nishimoto ${ }^{1}$, Hirohiko Nishiyama ${ }^{1}$ and Toshiharu Kawamoto ${ }^{1}$

\begin{abstract}
Background: A residual risk of cardiovascular disease tends to persist despite standard prevention therapy with statins. This may stem partly from increased oxidized low-density lipoprotein (LDL) levels. However, how oxidized $\mathrm{LDL}$ can be further reduced beyond statin therapy in high-risk diabetes patients remains unclear. We aimed to clarify the clinical factors associated with oxidized LDL levels in statin-treated high-risk diabetes patients.
\end{abstract}

Methods: This cross-sectional observational study included 210 diabetes patients with coronary artery diseases (CAD) who were treated with statins. We determined serum malondialdehyde-modified LDL (MDA-LDL), LDL cholesterol, high-density lipoprotein (HDL) cholesterol, triglyceride (TG), remnant lipoprotein cholesterol, hemoglobin $(\mathrm{Hb}) \mathrm{A}_{1 \mathrm{c}}$ adiponectin, and C-reactive protein (CRP) levels and investigated the factors influencing the MDA-LDL level.

Results: In univariate analysis, the MDA-LDL level was significantly correlated with LDL cholesterol $(p<0.0001)$, TG $(p<0.0001)$, HDL cholesterol $(p=0.017)$, and adiponectin $(p=0.001)$ levels but not with age, body mass index, waist circumference, blood pressure, or $\mathrm{HbA}_{1 c}$ levels. Even after adjusting for the LDL cholesterol level, the correlations between the MDA-LDL level and the TG, HDL cholesterol, and adiponectin levels were still significant. Among these significant factors, multivariate analysis revealed that the MDA-LDL level was independently associated with the LDL cholesterol, TG, and HDL cholesterol but not with adiponectin levels. The MDA-LDL level was also significantly associated with the CRP level $(p=0.014)$ and the remnant lipoprotein cholesterol level $(p<0.0001)$ independently of the LDL cholesterol level. The number of metabolic syndrome (MS) components was significantly associated with the MDA-LDL/LDL cholesterol ratio $(p<0.0001)$. Furthermore, the use of metformin and a-glucosidase inhibitors was inversely associated with high MDA-LDL levels ( $p=0.033$ and 0.018 , respectively).

(Continued on next page)

\footnotetext{
* Correspondence: morihiro-m@kure-nh.go.jp

'Department of Cardiology, National Hospital Organization Kure Medical

Center and Chugoku Cancer Center, 3-1 Aoyamacho, Kure, Hiroshima

737-0023, Japan

${ }^{2}$ Department of Internal Medicine, National Hospital Organization Kure

Medical Center and Chugoku Cancer Center, 3-1 Aoyamacho, Kure,

Hiroshima 737-0023, Japan

Full list of author information is available at the end of the article
} 
(Continued from previous page)

Conclusion: In statin-treated diabetes patients with CAD, the MDA-LDL level was significantly correlated with TG and HDL cholesterol levels. Adiponectin level was also significantly associated with the MDA-LDL level, but not independent of the above-mentioned factors. The management of dyslipidemic MS components, including the use of metformin or a-glucosidase inhibitors, may be important for reducing the oxidized LDL levels beyond statin therapy in high-risk diabetes patients.

Keywords: MDA-LDL, Metabolic syndrome, Triglycerides, HDL cholesterol, Adiponectin, Diabetes mellitus, Coronary artery disease, Statins

\section{Background}

Patients with diabetes mellitus (DM) are at high risk for death caused by cardiovascular disease and even higher risk if they have developed coronary artery disease (CAD) [1]. Rather than coronary intervention, prevention therapy is more crucial for reducing the mortality of high-risk patients [2]. According to many clinical trials, it is well established that lowering low-density lipoprotein (LDL) levels with statins is an important prevention strategy for CAD $[3,4]$. However, even if statins can successfully attenuate the LDL levels, the risk of CAD cannot be eliminated. This residual risk of CAD may involve an increase in the circulating levels of oxidized LDL, which plays an important role in the pathogenesis of atherosclerosis [5,6]. Several studies have demonstrated an association between the prevalence of CAD and the oxidized LDL level [7-10]. Furthermore, the oxidized LDL level may be a useful marker for secondary coronary events in type 2 diabetic patients [11]. Statins reduce the serum oxidized LDL level via LDL-lowering and antioxidative effects [12]. However, in addition to the established prevention therapy with statins, it is unclear how oxidized LDL levels can be further reduced in the high-risk patients with DM.

Patients with metabolic syndrome (MS) are at high risk for CAD and the related mortality [13]. The association between MS and oxidized LDL has recently been demonstrated [14-16]. Adiponectin, a protein released exclusively from adipocytes, has anti-diabetic and antiatherosclerotic properties $[17,18]$. Many clinical studies have demonstrated the predictive value of the plasma adiponectin level for severe CAD, myocardial infarction, and mortality [19-21]. In obese individuals, circulating adiponectin levels are decreased [22], which may partly explain the molecular basis of obesity-associated insulin resistance and atherosclerosis. Furthermore, a low adiponectin level is associated with a high triglyceride (TG) level [23], a low high-density lipoprotein (HDL) cholesterol level [24,25], and hypertension [26], suggesting the involvement of adiponectin in the pathogenesis of MS [27]. Systemic oxidative stress levels determined by serum and urinary lipid peroxidation parameters are inversely correlated with serum adiponectin levels in obese people
[28]. Moreover, a low serum adiponectin level is associated with a high level of circulating oxidized LDL [29]. However, it remains unclear whether MS and adiponectin levels are still significantly associated with oxidized LDL levels under statin treatment in high-risk DM patients.

Malondialdehyde-modified LDL (MDA-LDL) is recognized as a surrogate marker of oxidized LDL, and it has been suggested that circulating MDA-LDL levels could be a useful indicator for the identification of patients with CAD [7]. In this study, we investigated the clinical factors associated with MDA-LDL levels and evaluated the significance of the MS components and serum adiponectin levels in statin-treated DM patients with CAD. Moreover, we investigated whether any medications affect the MDA-LDL levels in these subjects. Identifying factors that significantly affect the MDA-LDL level should help establish a strategy that can further reduce LDL oxidization in addition to statin therapy, leading to further reduction in the risk of cardiovascular events in high-risk DM patients.

\section{Methods}

\section{Subjects}

We conducted a cross-sectional observational study of 237 DM patients with CAD who underwent coronary angiography or coronary artery computed tomography between 2010 and 2011. All subjects were treated with statins for secondary prevention. We analyzed 210 patients after excluding those who had uncontrolled diabetes with hemoglobin $(\mathrm{Hb}) \mathrm{A}_{1 \mathrm{c}}>10.0 \%$, severe hypertriglyceridemia with serum TG $>400 \mathrm{mg} / \mathrm{dL}$, chronic kidney disease with serum creatinine $>2.0 \mathrm{mg} / \mathrm{dL}$, or inflammatory disease with $\mathrm{C}$-reactive protein $(\mathrm{CRP})>3.0 \mathrm{mg} / \mathrm{dL}$. Informed consent was obtained from all subjects. This study protocol was approved by the Ethics Committee of Kure Medical Center.

\section{Laboratory measurements}

Venous blood was drawn from all subjects after an overnight fast. Serum levels of total cholesterol, TG, and HDL cholesterol were determined enzymatically (Sekisui Medical Co., Ltd., Tokyo, Japan). Serum MDA-LDL levels were measured by a sandwich enzyme-linked 
immunosorbent assay (ELISA) system (Sekisui Medical, Tokyo, Japan) with intra-assay coefficients of variation (CV) of $4.95-7.58 \%$ and inter-assay CV of $3.63-7.60 \%$. The $\mathrm{HbA}_{1 \mathrm{c}}$ value was estimated as a National Glycohemoglobin Standardization Program-equivalent percentage calculated using the following formula: $\mathrm{HbA}_{1 \mathrm{c}}(\%)=$ $1.02 \times \mathrm{HbA}_{1 \mathrm{c}}$ (Japan Diabetic Society, JDS) $(\%)+0.25$ [30]. Serum LDL cholesterol levels were calculated using the Friedewald formula. The serum concentration of total adiponectin was measured using a sandwich ELISA system (human adiponectin ELISA kit; Otsuka, Tokushima, Japan). The serum CRP levels were measured using a latex agglutination method (Sekisui Medical, Tokyo, Japan). The serum levels of remnant lipoprotein cholesterol were determined using a homogenous assay (RemL-C assay; Kyowa Medex, Tokyo, Japan) [31].

\section{Definition of DM and MS}

DM patients were defined according to the Japanese criteria [30] and/or prior use of anti-diabetic medication. The components of MS other than high plasma fasting glucose (all patients had DM) were defined according to the Japanese criteria [32] as follows: (1) waist circumference $\geq 85 \mathrm{~cm}$ for men or $\geq 90 \mathrm{~cm}$ for women; (2) elevated serum TG $\geq 150 \mathrm{mg} / \mathrm{dL}$; (3) reduced serum HDL cholesterol $<40 \mathrm{mg} / \mathrm{dL}$; and (4) elevated systolic blood pressure $\geq 130 \mathrm{mmHg}$ and/or diastolic blood pressure $\geq 85 \mathrm{mmHg}$ and/or prior use of antihypertensive medication.

\section{Statistical analyses}

Data are expressed as mean \pm standard deviation (SD). Single and multiple regression analyses were performed to evaluate the association between MDA-LDL levels and the indicated variables. Analysis of variance (ANOVA) with Tukey-Kramer's honestly significant difference test was used to evaluate the association between the number of MS components and the MDA-LDL/LDL cholesterol ratios. A multivariable logistic model was used to assess the association between a high MDA-LDL level and the indicated medications. Statistical analyses were performed using JMP for Windows (version 9; SAS Institute, Cary, NC). Statistical significance was defined by a $\mathrm{p}$ value of $<0.05$.

\section{Results}

\section{Subject characteristics}

The characteristics of the subjects and the medications prescribed are shown in Table 1 . Because all subjects were treated with statins, the average LDL cholesterol was as low as $92.6 \mathrm{mg} / \mathrm{dL}$. The statins used were atorvastatin $5-20 \mathrm{mg}$ (37\% of patients), pravastatin $5-20 \mathrm{mg}$ (27\%), rosuvastatin $2.5-10 \mathrm{mg}$ (26\%), pitavastatin 2$3 \mathrm{mg}$ (7\%), simvastatin 5-10 $\mathrm{mg}$ (2\%), and fluvastatin $20 \mathrm{mg}$ (1\%). Other anti-hyperlipidemic agents were
Table 1 Subject characteristics

\begin{tabular}{|c|c|}
\hline $\mathrm{N}$ & 210 \\
\hline Age - years & $70.6 \pm 8.7$ \\
\hline Male sex — no. (\%) & $136(64.7)$ \\
\hline \multicolumn{2}{|l|}{ Morphometric findings } \\
\hline Body mass index $-\mathrm{kg} / \mathrm{m}^{2}$ & $24.6 \pm 4.1$ \\
\hline Waist circumference $-\mathrm{cm}$ & $88.6 \pm 10.5$ \\
\hline \multicolumn{2}{|l|}{ Blood pressure } \\
\hline Systolic - mmHg & $133.5 \pm 19.6$ \\
\hline Diastolic - mmHg & $73.9 \pm 13.5$ \\
\hline \multicolumn{2}{|l|}{ Laboratory measurements } \\
\hline Serum creatinine $-\mathrm{mg} / \mathrm{dL}$ & $0.9 \pm 0.2$ \\
\hline Total cholesterol - mg/dL & $166.4 \pm 31.7$ \\
\hline \multicolumn{2}{|l|}{ Triglycerides - mg/dL } \\
\hline Median (interquartile range) & $105(77-143)$ \\
\hline $\mathrm{HDL}$ cholesterol - mg/dL & $50.1 \pm 13.7$ \\
\hline LDL cholesterol - mg/dL & $92.6 \pm 23.0$ \\
\hline MDA-LDL - U/L & $99.0 \pm 39.0$ \\
\hline Hemoglobin $A_{1 c}-\%$ & $6.9 \pm 1.0$ \\
\hline \multicolumn{2}{|l|}{ Adiponectin $-\mu \mathrm{g} / \mathrm{dL}$} \\
\hline Median (interquartile range) & $13.3(8.5-24.1)$ \\
\hline \multicolumn{2}{|l|}{ Current medications - no. (\%) } \\
\hline Statins & $210(100)$ \\
\hline ACE-Is/ARBs & $152(72.4)$ \\
\hline$\beta$-Blockers & $132(62.9)$ \\
\hline Ca channel blockers & $85(40.5)$ \\
\hline Metformin & $84(40.0)$ \\
\hline Pioglitazone & 79 (37.6) \\
\hline a-Glucosidase inhibitors & $70(33.3)$ \\
\hline Sulfonylurea & $61(29.0)$ \\
\hline Insulin therapy & $37(17.6)$ \\
\hline Phenylalanine derivatives & $14(6.7)$ \\
\hline DPP4 inhibitors & $15(7.1)$ \\
\hline EPA & $9(4.3)$ \\
\hline Ezetimibe & $1(0.5)$ \\
\hline
\end{tabular}

Values represent means \pm SD unless indicated otherwise.

Abbreviations: $A R B$ angiotensin II receptor blocker, $A C E-I$ angiotensin-converting enzyme inhibitor, DPP4 dipeptidyl peptidase-4; EPA eicosapentaenoic acid, HDL high-density lipoprotein, LDL low-density lipoprotein, MDA-LDL malondialdehydemodified LDL.

prescribed in a small number of patients: ezetimibe for 1 patient and eicosapentaenoic acid (EPA) for 9 patients. The mean $\mathrm{HbA}_{1 \mathrm{c}}$ level was $6.9 \%$.

\section{Associations between the MDA-LDL level and various risk factors}

The MDA-LDL level was significantly correlated with the levels of LDL cholesterol, TG, HDL cholesterol, and adiponectin $(\mathrm{p}<0.0001, \mathrm{p}<0.0001, \mathrm{p}=0.017$, and $\mathrm{p}=0.001$, 
respectively) but not with age, body mass index (BMI), waist circumference, blood pressure, or creatinine or $\mathrm{HbA}_{1 \mathrm{c}}$ levels in single regression analysis (Table 2). Even after adjusting for the LDL cholesterol level, the MDALDL level was significantly correlated with the levels of TG, HDL cholesterol, and adiponectin ( $\mathrm{p}<0.0001, \mathrm{p}<$ 0.0001 , and $p=0.002$, respectively) (Figure 1). Multiple regression analysis revealed that the levels of LDL cholesterol, HDL cholesterol, and TG were independently associated with the MDA-LDL level (Table 3, model 1). The adiponectin level, however, was not significantly associated with the MDA-LDL level in this analysis (Table 3, model 1).

To understand in more detail the basis of the association between the MDA-LDL and TG levels, we investigated the level of remnant lipoprotein cholesterol. The remnant lipoprotein cholesterol level was significantly correlated with the TG level with a very high correlation coefficient $(r=0.940)$ and the LDL cholesterol level with a relatively low correlation coefficient $(r=0.246)$ (Figure 2A and $B$ ), suggesting that the remnant lipoproteins could be the major lipoproteins carrying TG in the fasting state upon statin treatment. Furthermore, the remnant lipoprotein cholesterol level was significantly correlated with the MDA-LDL level independently of the LDL cholesterol level in a multiple regression model (Figure 2C).

\section{Association between the MDA-LDL/LDL cholesterol ratio and the number of MS components}

The number of MS components present was significantly associated with the MDA-LDL/LDL cholesterol ratio $(\mathrm{p}<0.0001)$ (Figure 3 ). Patients with $\geq 4$ of the 5 MS component factors had a significantly higher MDALDL/LDL cholesterol ratio than those with fewer factors

Table 2 Relationship between the level of MDA-LDL and various parameters in univariate analyses

\begin{tabular}{lcc}
\hline & $\mathbf{r}$ & $\mathbf{p}$ \\
\hline Age & 0.010 & 0.887 \\
Body mass index & -0.023 & 0.739 \\
Waist circumference & 0.025 & 0.724 \\
Systolic blood pressure & 0.075 & 0.281 \\
Creatinine & 0.036 & 0.600 \\
Hemoglobin A1c & 0.068 & 0.330 \\
LDL cholesterol & 0.458 & $<0.0001$ \\
Triglycerides* & 0.435 & $<0.0001$ \\
HDL cholesterol & -0.164 & 0.017 \\
Adiponectin* & -0.227 & 0.001
\end{tabular}

Abbreviations: $H D L$ high-density lipoprotein, $L D L$ low-density lipoprotein, $M D A-L D L$ malondialdehyde-modified LDL.

Statistical analyses were performed using simple regression.

*Log-transformed values were subjected to statistical analyses.
( $\mathrm{p}<0.05$ for 4 vs. 1,2 , or 3 MS components; $\mathrm{p}<0.001$ for 5 vs. 1, 2, or 3 MS components).

\section{Association between a high MDA-LDL level and inflammation}

Because inflammation plays a pivotal role in the pathogenesis of both MS and atherosclerosis, we investigated the association between CRP and MDA-LDL levels. A high CRP level of $\geq 0.2 \mathrm{mg} / \mathrm{dL}$ was significantly associated with a high MDA-LDL level (defined by a median value of $>91 \mathrm{U} / \mathrm{L}$ ), compared with a low CRP level of $<0.1 \mathrm{mg} / \mathrm{dL}$ (Table 4). This association remained significant even after adjusting for the LDL cholesterol level (Table 4). However, this significance was diminished by adjusting for both LDL cholesterol and TG levels and was eliminated after adjusting for LDL cholesterol, TG, and HDL cholesterol levels (Table 4).

\section{Association between a high MDA-LDL level and medications combined with statins}

In a multivariate logistic analysis adjusted for LDL cholesterol, TG, HDL cholesterol, and adiponectin levels, we found, among the medications used in combination with statins, that the use of metformin and $\alpha$-glucosidase inhibitors ( $\alpha$-GIs) was inversely associated with a high MDA-LDL level (defined by a median value of $>91 \mathrm{U} / \mathrm{L}$ ) (Table 5). Conversely, the associations of LDL cholesterol, TG, and HDL cholesterol with MDA-LDL remained significant in another multivariate model even after adjustment for the use of metformin and $\alpha$-GIs (Table 3, model 2).

\section{Discussion}

In this study, the level of MDA-LDL was significantly correlated with the levels of TG, HDL cholesterol, and adiponectin, independent of the LDL cholesterol level, in statin-treated DM patients with CAD. However, there was no significant association between the level of adiponectin and the level of MDA-LDL when the regression was adjusted for the levels of LDL cholesterol, TG, and HDL cholesterol. An increasing number of MS components resulted in a higher MDA-LDL/LDL cholesterol ratio. Among the medications used in combination with statins, the use of metformin and $\alpha$-GIs was inversely associated with a high MDA-LDL level in multivariate logistic analysis.

This study revealed that TG and HDL cholesterol were significantly correlated with MDA-LDL levels independent of the LDL cholesterol level in statin-treated highrisk DM patients. An increased TG level and decreased HDL cholesterol level are observed due to insulin resistance, and hence, they are recognized as dyslipidemic components of MS. The prolonged presence of increased TG-rich lipoproteins in the circulation induces 


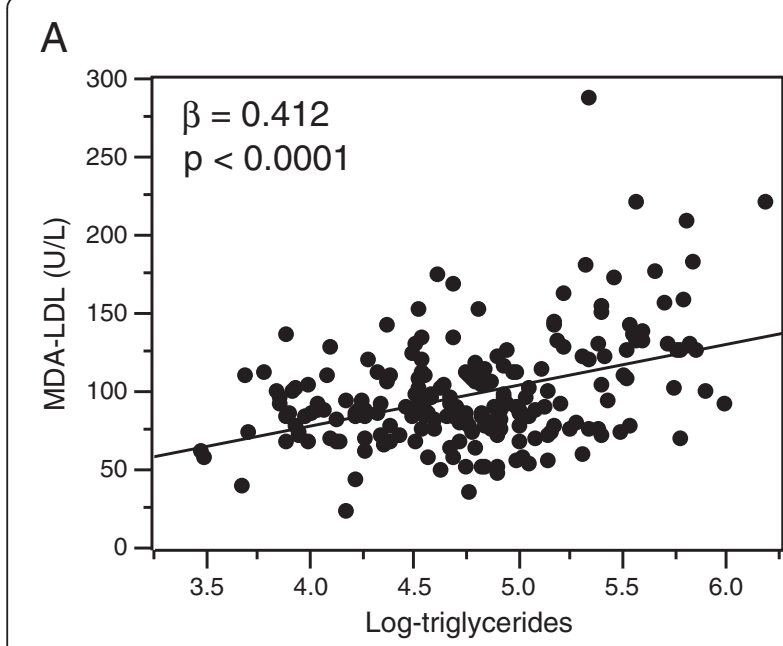

B

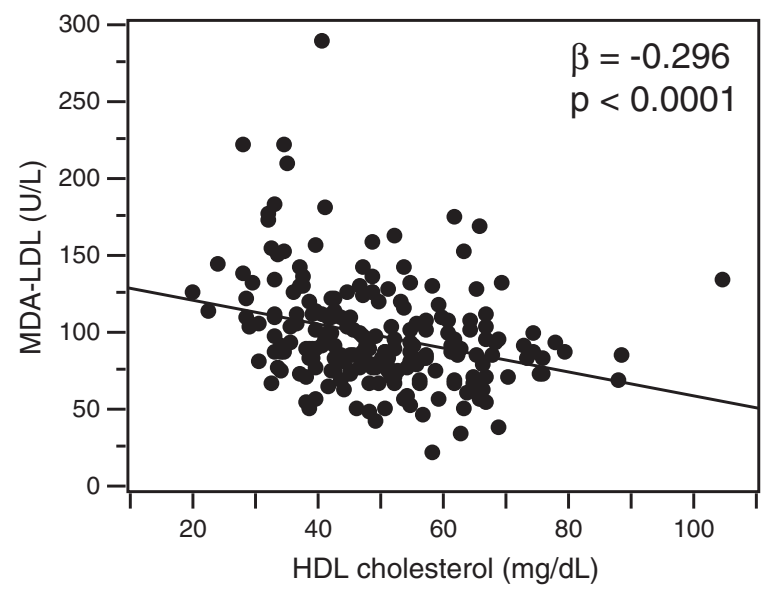

C

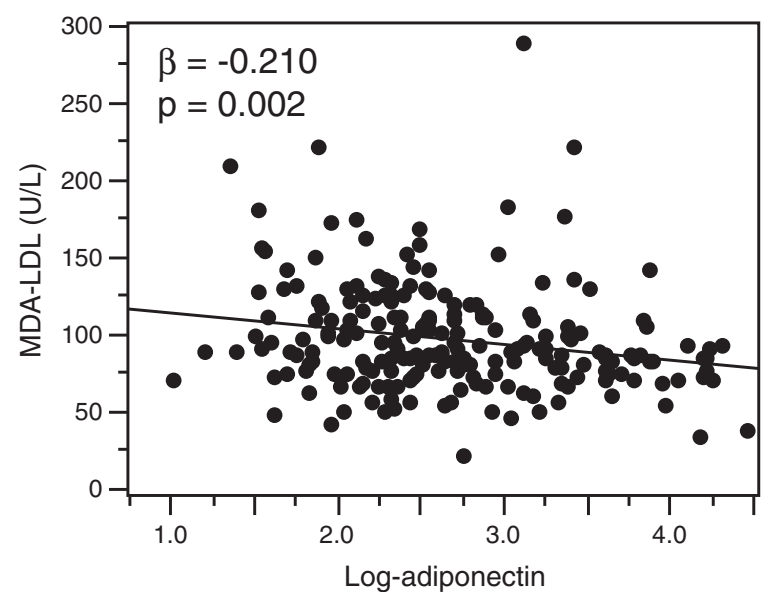

Figure 1 Correlations between the malondialdehyde-modified low-density lipoprotein (MDA-LDL) level and associated factors after adjusting for LDL cholesterol levels. The MDA-LDL level $(U / L)$ was significantly correlated with the levels of log-transformed triglycerides (A), high-density lipoprotein (HDL) cholesterol ( $\mathrm{mg} / \mathrm{dL})$ (B), and log-transformed adiponectin (C) with the indicated partial correlation coefficient ( $\beta$ ) and $p$ value. Statistical analyses were performed by multiple regression models adjusted for $L D L$ cholesterol level.

oxidative stress in the endothelium [33,34]. The current study revealed the significant association between the levels of MDA-LDL and remnant lipoprotein cholesterol. Activation of lectin-like oxidized LDL receptor-1 by remnant lipoprotein particles induces nicotinamide adenine dinucleotide phosphate (NADPH) oxidase-dependent production of superoxide in endothelial cells [35], which may explain the significant association between LDL oxidation and remnant lipoproteins rich in TG. Moreover, HDL protects against the oxidation of LDL [36]. Taken together, these results might explain the close association between oxidized LDL and the dyslipidemic components of MS. Holvoet et al. demonstrated the association between various features of MS and oxidized LDL in well-functioning elderly people [14]. Our study, however, indicated that in statin-treated DM patients, the level of MDA-LDL was associated with the dyslipidemic components of MS but not with other features of MS, including blood pressure, waist circumference, or the level of $\mathrm{HbA}_{1 \mathrm{c}}$ (instead of fasting glucose). Nevertheless, patients with $\geq 4$ of the 5 MS factors had a significantly higher MDA-LDL/LDL cholesterol ratio than those with fewer factors. This suggests that the additional presence of hypertension and/or abdominal obesity can somehow aggravate the oxidation of LDL. These findings also suggest that accumulation of these MSconstituting factors should be attenuated to reduce the

Table 3 Impact of LDL cholesterol, triglycerides, HDL cholesterol, and adiponectin on the level of MDA-LDL in the multivariate analyses

\begin{tabular}{lccccc}
\hline & \multicolumn{2}{c}{ Model 1 } & & \multicolumn{2}{c}{ Model 2 } \\
\cline { 2 - 3 } \cline { 5 - 6 } & $\boldsymbol{\beta}$ & $\mathbf{p}$ & & $\boldsymbol{\beta}$ & $\mathbf{p}$ \\
\hline LDL cholesterol & 0.452 & $<0.0001$ & & 0.444 & $<0.0001$ \\
Triglycerides* & 0.317 & $<0.0001$ & & 0.318 & $<0.0001$ \\
HDL cholesterol & -0.137 & 0.049 & & -0.139 & 0.048 \\
Adiponectin* & -0.049 & 0.481 & & -0.032 & 0.648
\end{tabular}

Abbreviations: $H D L$ high-density lipoprotein, $L D L$ low-density lipoprotein $M D A-L D L$ malondialdehyde-modified LDL.

In model $1\left(R^{2}=0.361\right), \mathrm{LDL}$ cholesterol, triglycerides, HDL cholesterol, and adiponectin were included as the variables in the multiple regression analysis. In model $2\left(R^{2}=0.365\right)$, medications (metformin and a-glucosidase inhibitors) were added to the variables for the model 1 analysis.

*Log-transformed values were subjected to statistical analyses. 


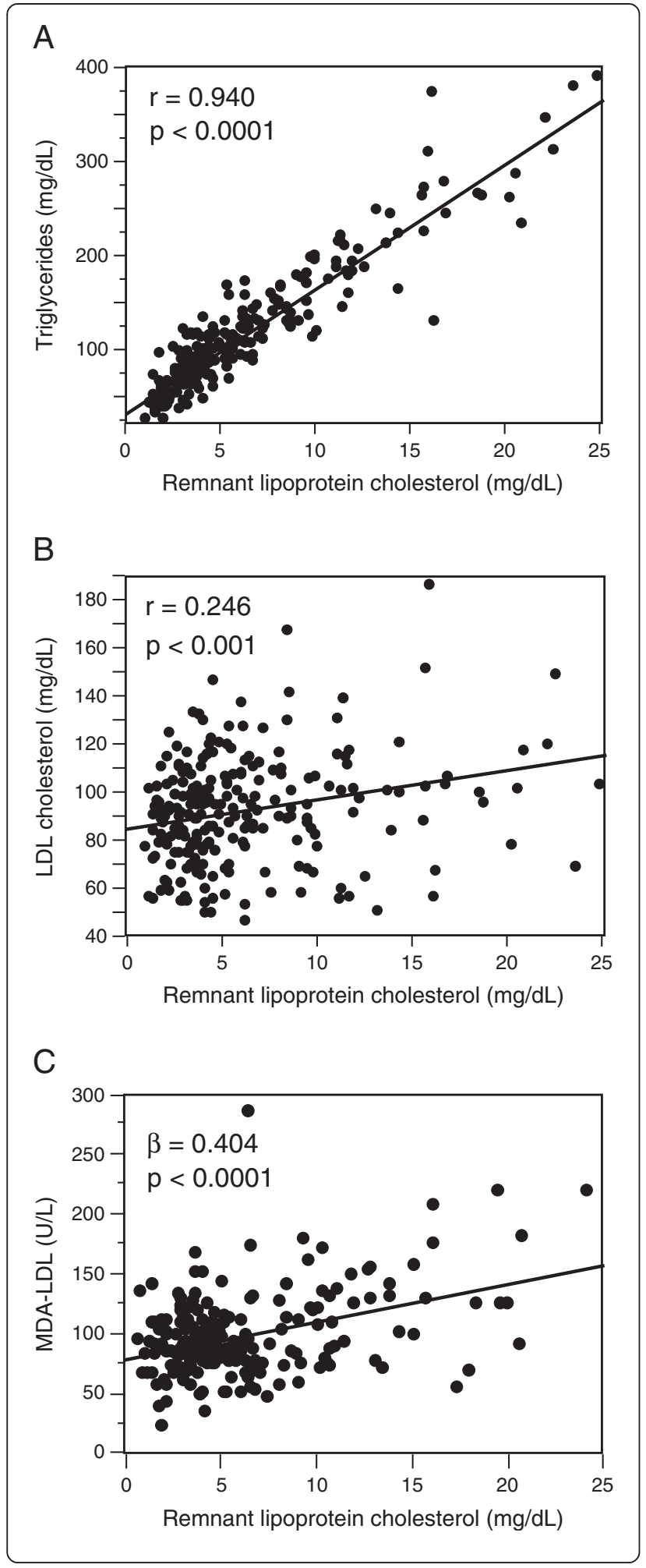

Figure 2 Associations of the remnant lipoprotein cholestero level with the levels of triglycerides, low-density lipoprotein (LDL) cholesterol, and malondialdehyde-modified LDL (MDA-LDL). A and B, The remnant lipoprotein cholesterol level $(\mathrm{mg} / \mathrm{dL})$ was significantly correlated with the levels of triglycerides $(\mathrm{mg} / \mathrm{dL})(\mathbf{A})$ and $\mathrm{LDL}$ cholesterol $(\mathrm{mg} / \mathrm{dL})$ (B) with the indicated correlation coefficient $(r)$ and $p$ value in simple regression analyses. C, The remnant lipoprotein cholesterol level ( $\mathrm{mg} / \mathrm{dL}$ ) was significantly correlated with the MDA-LDL level $(\mathrm{U} / \mathrm{L})$ with the indicated partial correlation coefficient $(\beta)$ and $p$ value in a multiple regression model adjusted for LDL cholesterol level.

oxidation of LDL even with statin treatment in high-risk DM patients.

Inflammation plays a pivotal role in the progression of atherosclerosis. CRP $\geq 0.2 \mathrm{mg} / \mathrm{dL}$ is significantly associated with the incidence of cardiovascular events [37,38]. The current data indicated that a high CRP level of $\geq 0.2 \mathrm{mg} / \mathrm{dL}$ was significantly associated with a high level of MDA-LDL independently of LDL cholesterol. On the other hand, additional adjustment for TG and HDL cholesterol levels eliminated the significance of the association between CRP and MDA-LDL levels, suggesting that the inflammation may affect LDL oxidation, possibly through the dyslipidemic changes of MS.

We previously demonstrated that oxidative stress was closely associated with a low adiponectin level [28]. Adiponectin production from adipocytes was suppressed by reactive oxygen species but reversed by the addition of an antioxidant agent [28]. Treating KKAy obese mice with apocynin, an NADPH oxidase inhibitor, prevented the reduction in adiponectin level by suppressing oxidative stress, leading to an improvement in insulin resistance

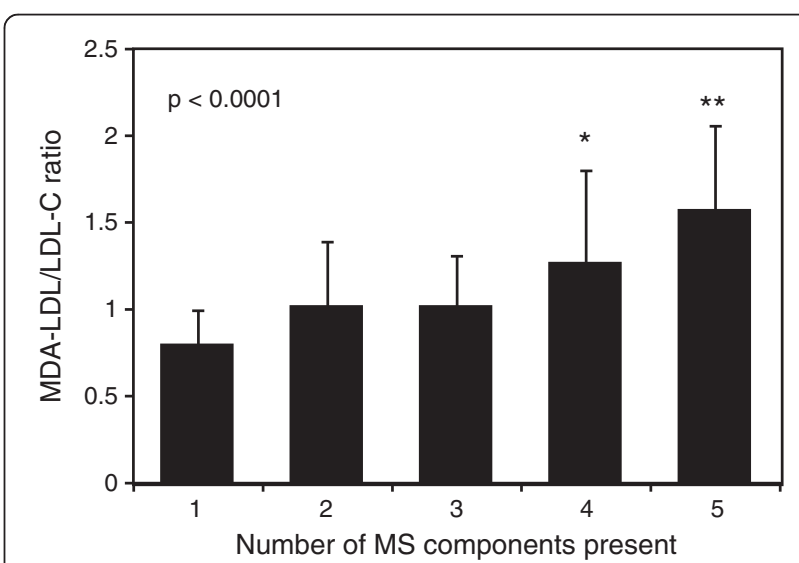

Figure 3 Association between the malondialdehyde-modified low-density lipoprotein (MDA-LDL)/LDL cholesterol (C) ratio and the number of metabolic syndrome (MS) components. The MDA-LDL/LDL-C ratios were compared in patients with the indicated number of MS components. Data are expressed as means \pm SD. Statistical analyses were performed by analysis of variance with Tukey-Kramer's honestly significant difference test. *, $p<0.05$ vs. 1, 2, or 3 ; $^{* *}, \mathrm{p}<0.001$ vs. 1,2 , or 3 . 
Table 4 Association between CRP levels and high MDA-LDL level in univariate and multivariate logistic analyses

\begin{tabular}{|c|c|c|c|c|}
\hline & \multicolumn{3}{|c|}{ CRP concentration, $\mathrm{mg} / \mathrm{dL}$} & \multirow[b]{2}{*}{$\mathrm{p}^{*}$} \\
\hline & $<0.1$ & $0.1-0.2$ & $\geq 0.2$ & \\
\hline Univariate, OR (95\% Cl) & 1 & $1.77(0.89-3.55)$ & $3.40(1.54-8.02)$ & 0.006 \\
\hline \multicolumn{5}{|l|}{ Multivariate, OR (95\% Cl) } \\
\hline Adjusted for LDL-C & 1 & $1.43(0.68-3.01)$ & $3.44(1.49-8.45)$ & 0.014 \\
\hline Adjusted for LDL-C, TG & 1 & $1.08(0.49-2.35)$ & $2.74(1.14-6.95)$ & 0.071 \\
\hline Adjusted for LDL-C, TG, HDL-C & 1 & $0.95(0.42-2.09)$ & $2.41(0.98-6.20)$ & 0.124 \\
\hline
\end{tabular}

Abbreviations: $C l$ confidence interval, $C R P$ C-reactive protein, $H D L-C$ high-density lipoprotein cholesterol, $L D L-C$ low-density lipoprotein cholesterol, $M D A-L D L$ malondialdehyde-modified LDL, OR odds ratio; $T G$ triglycerides.

Univariate and multivariate logistic analyses with an adjustment for the indicated parameters were performed. A high MDA-LDL level was defined by a median value of $>91 \mathrm{U} / \mathrm{L}$

* Likelihood ratio test for trend.

and dyslipidemia [28]. Moreover, adiponectin protected against damage induced by oxidative stress in the vascular walls and myocardium $[39,40]$. Thus, adiponectin is likely to be closely linked to oxidative stress. A low adiponectin level was inversely associated with the oxidized LDL level [29]. Similarly, in our study, the level of adiponectin was significantly correlated with the MDA-LDL level in the regression analysis adjusted for the LDL cholesterol level. However, this correlation was not significant after we adjusted for the levels of TG and HDL cholesterol, possibly because the level of adiponectin is negatively correlated with the TG level and positively correlated with the HDL cholesterol level [27]. Collectively, the relationship between

\section{Table 5 Multivariate logistic analysis of the relationship between medications used with statins and high MDA-LDL level}

\begin{tabular}{lcc}
\hline & Adjusted OR (95\% Cl) & p \\
\hline ACE-Is or ARBs & $1.29(0.61-2.78)$ & 0.508 \\
$\beta$-Blockers & $1.04(0.51-2.12)$ & 0.923 \\
Ca channel blockers & $1.23(0.62-2.45)$ & 0.548 \\
Metformin & $0.48(0.24-0.94)$ & 0.032 \\
Pioglitazone & $0.61(0.28-1.28)$ & 0.190 \\
a-Glucosidase inhibitors & $0.43(0.21-0.87)$ & 0.018 \\
Sulfonylurea & $1.65(0.76-3.66)$ & 0.205 \\
Insulin therapy & $0.51(0.21-1.20)$ & 0.124 \\
Other variables & & \\
$\quad$ LDL cholesterol & $241.6(22.0-3289.8)^{*}$ & $<0.0001$ \\
Triglycerides & $12.95(2.02-93.09)^{*}$ & 0.007 \\
HDL cholesterol & $0.10(0.00-0.98)^{*}$ & 0.048 \\
$\quad$ Adiponectin & $1.18(0.19-7.12)^{*}$ & 0.859 \\
\hline
\end{tabular}

Abbreviations: $A C E-I$ angiotensin-converting enzyme inhibitor, $A R B$ angiotensin II receptor blocker, $\mathrm{Cl}$ confidence interval; $H D L$ high-density lipoprotein, $L D L$ low-density lipoprotein, $M D A-L D L$ malondialdehyde-modified $L D L$, OR odds ratio.

Multivariate logistic regression analysis was performed with an adjustment for all indicated medicines and the levels of LDL cholesterol, triglycerides, HDL cholesterol, and adiponectin. A high MDA-LDL level was defined by a median value of $>91 \mathrm{U} / \mathrm{L}$.

*Range OR $(95 \% \mathrm{Cl})$. the adiponectin and oxidized LDL levels may be influenced by the TG and HDL cholesterol levels.

Keaney et al. demonstrated that obesity was associated with systemic oxidative stress as assessed by the level of urinary 8-epi-prostaglandin F2 $\alpha$ (PGF2 $\alpha$ ) [41]. Similarly, we demonstrated that the level of serum thiobarbituric acid reactive substance and urinary 8 -epi-PGF2 $\alpha$ were positively correlated with BMI independent of diabetes in humans [28]. However, in the present study, the MDA-LDL level was not significantly associated with BMI or waist circumference despite a significant association with obesity-related factors such as TG, HDL cholesterol, and adiponectin levels. Both MDA-LDL and lipid peroxidation parameters indicate the level of oxidative stress. However, they may have different associations with clinical parameters such as LDL cholesterol level or BMI because of their different origins.

In the present study, the use of metformin was inversely associated with a high MDA-LDL level, independent of LDL cholesterol, TG, and HDL cholesterol levels. Metformin reduces the synthesis of hepatic verylow-density lipoprotein and the production of glucose, which is mediated by 5 -adenosine monophosphateactivated protein kinase [42], and leads to increased insulin sensitivity and reduction in the plasma TG levels. This might partly contribute to the reduction in MDALDL levels, although the precise mechanism remains to be clarified. Similarly, the use of $\alpha$-GIs was inversely associated with a high MDA-LDL level. The $\alpha$-GIs reportedly suppress oxidative stress in the vascular wall by suppressing postprandial hyperglycemia [33,43], which might explain the reduction of MDA-LDL. Despite increasing the circulating levels of adiponectin $[44,45]$ as well as several antioxidative enzymes [46-48], the use of pioglitazone was not significantly associated with the MDA-LDL level in this analysis. The antioxidative actions of pioglitazone might not be as effective as metformin or $\alpha$-GIs in suppressing LDL oxidation. Further investigation of this issue is required. Among various anti-diabetic agents, metformin and $\alpha$-GIs have been 
proven to be effective in the primary prevention of cardiovascular disease in large-scale clinical trials [49,50]. Importantly, they suppress weight gain $[49,50]$. An improvement in insulin resistance and postprandial hyperglycemia with suppression of weight gain may be important for reducing LDL oxidation, which should contribute to the prevention of cardiovascular events.

When the 9 patients who had taken EPA were excluded from the univariate analysis, the correlations of the LDL cholesterol, TG, HDL cholesterol, and adiponectin levels with the MDA-LDL level remained significant. However, in the multivariate analysis, the association of HDL cholesterol with MDA-LDL was weakened from $\mathrm{p}=0.049$ to $\mathrm{p}=0.065$, suggesting that EPA might affect the MDA-LDL level, possibly through an influence on TG and HDL cholesterol levels. Therefore, further analysis in a large population is required to resolve this issue.

This study had several limitations. The subjects in this study were relatively elderly patients (mean age, 70.6 years), and any differences with respect to age are unknown. In addition, this was a cross-sectional observational study conducted in a single center. Multicenter prospective cohort studies and randomized controlled trials are essential to determine the clinical determinants of oxidized LDL and effective medications for reducing LDL oxidation.

\section{Conclusion}

DM patients with CAD are at very high risk for cardiovascular events. Hence, they require a risk-reducing strategy beyond the standard prevention therapy with statins. In these patients treated with statins, the circulating MDA-LDL levels were significantly correlated with the TG and HDL cholesterol levels. Adiponectin levels were also significantly correlated with MDA-LDL levels, but not independent of TG and HDL cholesterol. Furthermore, treatment with metformin or $\alpha$-GIs might be associated with a reduction in MDA-LDL levels. Collectively, this study suggests that in addition to statin therapy, the management of dyslipidemic MS components, including use of metformin or $\alpha$-GIs, is important for reducing the oxidization of LDL and, ultimately, the risk of cardiovascular events in high-risk DM patients.

\footnotetext{
Abbreviations

ANOVA: Analysis of variance; BMI: Body mass index; CAD: Coronary artery disease; CRP: C-reactive protein; DM: Diabetes mellitus; 8-epi-PGF2a: 8-epiprostaglandin F2a; Hb: Hemoglobin; HDL: High-density lipoprotein; LDL: Low-density lipoprotein; MDA-LDL: Malondialdehyde-modified LDL; MS: Metabolic syndrome; NADPH: Nicotinamide adenine dinucleotide phosphate; TG: Triglyceride.
}

\section{Competing interests}

The authors declare that they have no competing interests.

\section{Authors' contributions}

MM, RT, and TK have made substantial contributions to the conception and design. KK, TS, HK, ON, and HN have made substantial contributions to data acquisition. MM, RT, and TK have contributed to the analysis and

interpretation of data. MM was involved in drafting the manuscript. RT, KK, TS, HK, ON, HN, and TK provided critical revision for important intellectual content. All authors have given final approval for publishing.

\section{Acknowledgments}

We thank Noriko Okamoto for supporting the collection of clinical data and Naoko Kishida for technical support in measuring adiponectin levels. This study was financially supported by a Grant-in-Aid for Clinical Research from the National Hospital Organization.

\section{Author details}

${ }^{1}$ Department of Cardiology, National Hospital Organization Kure Medical Center and Chugoku Cancer Center, 3-1 Aoyamacho, Kure, Hiroshima 737-0023, Japan. ²Department of Internal Medicine, National Hospital Organization Kure Medical Center and Chugoku Cancer Center, 3-1 Aoyamacho, Kure, Hiroshima 737-0023, Japan. ${ }^{3}$ Division of Preventive Medicine, Institute for Clinical Research, National Hospital Organization Kure Medical Center and Chugoku Cancer Center, 3-1 Aoyamacho, Kure, Hiroshima 737-0023, Japan.

Received: 10 September 2013 Accepted: 2 December 2013

Published: 6 December 2013

\section{References}

1. Group. NDR: Risk assessment chart for death from cardiovascular disease based on a 19-year follow-up study of a Japanese representative population. Circ J 2006, 70:1249-1255.

2. Boden WE, O'Rourke RA, Teo KK, Hartigan PM, Maron DJ, Kostuk WJ, Knudtson M, Dada M, Casperson P, Harris CL, et al: Optimal medical therapy with or without $\mathrm{PCI}$ for stable coronary disease. N Engl J Med 2007, 356:1503-1516.

3. Baigent C, Keech A, Kearney PM, Blackwell L, Buck G, Pollicino C, Kirby A, Sourjina T, Peto R, Collins R, Simes R: Efficacy and safety of cholesterollowering treatment: prospective meta-analysis of data from 90,056 participants in 14 randomised trials of statins. Lancet 2005, 366:1267-1278.

4. Smith SC Jr, Allen J, Blair SN, Bonow RO, Brass LM, Fonarow GC, Grundy SM, Hiratzka L, Jones D, Krumholz HM, et al: AHA/ACC guidelines for secondary prevention for patients with coronary and other atherosclerotic vascular disease: 2006 update: endorsed by the National Heart, Lung, and Blood Institute. Circulation 2006, 113:2363-2372.

5. Steinberg D, Parthasarathy S, Carew TE, Khoo JC, Witztum JL: Beyond cholesterol. Modifications of low-density lipoprotein that increase its atherogenicity. N Engl J Med 1989, 320:915-924.

6. Mertens A, Holvoet P: Oxidized LDL and HDL: antagonists in atherothrombosis. FASEB J 2001, 15:2073-2084.

7. Holvoet P, Vanhaecke J, Janssens S, Van de Werf F, Collen D: Oxidized LDL and malondialdehyde-modified LDL in patients with acute coronary syndromes and stable coronary artery disease. Circulation 1998, 98:1487-1494.

8. Toshima S, Hasegawa A, Kurabayashi M, Itabe H, Takano T, Sugano J, Shimamura K, Kimura J, Michishita I, Suzuki T, Nagai R: Circulating oxidized low density lipoprotein levels. A biochemical risk marker for coronary heart disease. Arterioscler Thromb Vasc Biol 2000, 20:2243-2247.

9. Ehara S, Ueda M, Naruko T, Haze K, Itoh A, Otsuka M, Komatsu R, Matsuo T, Itabe H, Takano T, et al: Elevated levels of oxidized low density lipoprotein show a positive relationship with the severity of acute coronary syndromes. Circulation 2001, 103:1955-1960.

10. Holvoet $P$, Mertens A, Verhamme P, Bogaerts $K$, Beyens $G$, Verhaeghe $R$, Collen D, Muls E, Van de Werf F: Circulating oxidized LDL is a useful marker for identifying patients with coronary artery disease. Arterioscler Thromb Vasc Biol 2001, 21:844-848.

11. Shigematsu S, Takahashi N, Hara M, Yoshimatsu H, Saikawa T: Increased incidence of coronary in-stent restenosis in type 2 diabetic patients is related to elevated serum malondialdehyde-modified low-density lipoprotein. Circ J 2007, 71:1697-1702. 
12. Tamura A, Watanabe T, Nasu M: Effects of atorvastatin and pravastatin on malondialdehyde-modified LDL in hypercholesterolemic patients. Circ J 2003, 67:816-820.

13. Isomaa B, Almgren P, Tuomi T, Forsen B, Lahti K, Nissen M, Taskinen MR, Groop L: Cardiovascular morbidity and mortality associated with the metabolic syndrome. Diabetes Care 2001, 24:683-689.

14. Holvoet P, Kritchevsky SB, Tracy RP, Mertens A, Rubin SM, Butler J, Goodpaster B, Harris TB: The metabolic syndrome, circulating oxidized $\mathrm{LDL}$, and risk of myocardial infarction in well-functioning elderly people in the health, aging, and body composition cohort. Diabetes 2004 53:1068-1073.

15. Holvoet $P$, Lee DH, Steffes M, Gross M, Jacobs DR Jr: Association between circulating oxidized low-density lipoprotein and incidence of the metabolic syndrome. JAMA 2008, 299:2287-2293.

16. Yamagishi S, Matsuoka H, Kitano S, Hibi N, Jinnouchi Y, Umei H, lida S, Takenaka K, Matsui T, Nakamura K, Imaizumi T: Elevated circulating oxidized LDL levels in Japanese subjects with the metabolic syndrome. Int J Cardiol 2007, 118:270-272

17. Maeda N, Shimomura I, Kishida K, Nishizawa H, Matsuda M, Nagaretani H, Furuyama N, Kondo H, Takahashi M, Arita Y, et al: Diet-induced insulin resistance in mice lacking adiponectin/ACRP30. Nat Med 2002, 8:731-737.

18. Matsuda M, Shimomura I, Sata M, Arita Y, Nishida M, Maeda N, Kumada M, Okamoto $Y$, Nagaretani $H$, Nishizawa $H$, et al: Role of adiponectin in preventing vascular stenosis. The missing link of adipo-vascular axis. J Biol Chem 2002, 277:37487-37491.

19. Pischon T, Girman CJ, Hotamisligil GS, Rifai N, Hu FB, Rimm EB: Plasma adiponectin levels and risk of myocardial infarction in men. JAMA 2004, 291:1730-1737.

20. Lindberg S, Pedersen SH, Mogelvang R, Bjerre M, Frystyk J, Flyvbjerg A, Galatius S, Jensen JS: Usefulness of adiponectin as a predictor of all cause mortality in patients with ST-segment elevation myocardial infarction treated with primary percutaneous coronary intervention. Am J Cardiol 2012, 109:492-496.

21. Matsuda M, Tamura R, Kishida N, Segawa T, Kanno K, Nishimoto O, Nakamoto K, Nishiyama H, Kawamoto T: Predictive value of adiponectin in patients with multivessel coronary atherosclerosis detected on computed tomography angiography. J Atheroscler Thromb 2013, 20:767-776.

22. Arita Y, Kihara S, Ouchi N, Takahashi M, Maeda K, Miyagawa J, Hotta K, Shimomura I, Nakamura T, Miyaoka K, et al: Paradoxical decrease of an adipose-specific protein, adiponectin, in obesity. Biochem Biophys Res Commun 1999, 257:79-83.

23. Qiao L, Zou C, van der Westhuyzen DR, Shao J: Adiponectin reduces plasma triglyceride by increasing VLDL triglyceride catabolism. Diabetes 2008, 57:1824-1833.

24. Matsuura F, Oku H, Koseki M, Sandoval JC, Yuasa-Kawase M, TsubakioYamamoto K, Masuda D, Maeda N, Tsujii K, Ishigami M, et al: Adiponectin accelerates reverse cholesterol transport by increasing high density lipoprotein assembly in the liver. Biochem Biophys Res Commun 2007 358:1091-1095.

25. Oku H, Matsuura F, Koseki M, Sandoval JC, Yuasa-Kawase M, TsubakioYamamoto K, Masuda D, Maeda N, Ohama T, Ishigami M, et al: Adiponectin deficiency suppresses $A B C A 1$ expression and ApoA-I synthesis in the liver. FEBS Lett 2007, 581:5029-5033.

26. Iwashima Y, Katsuya T, Ishikawa K, Ouchi N, Ohishi M, Sugimoto K, Fu Y, Motone M, Yamamoto K, Matsuo A, et al: Hypoadiponectinemia is an independent risk factor for hypertension. Hypertension 2004, 43:1318-1323.

27. Ryo M, Nakamura T, Kihara S, Kumada M, Shibazaki S, Takahashi M, Nagai M, Matsuzawa Y, Funahashi T: Adiponectin as a biomarker of the metabolic syndrome. Circ J 2004, 68:975-981.

28. Furukawa S, Fujita T, Shimabukuro M, Iwaki M, Yamada $Y$, Nakajima $Y$, Nakayama O, Makishima M, Matsuda M, Shimomura I: Increased oxidative stress in obesity and its impact on metabolic syndrome. J Clin Invest 2004, 114:1752-1761.

29. Lautamaki R, Ronnemaa T, Huupponen R, Lehtimaki T, lozzo P, Airaksinen KE, Knuuti J, Nuutila P: Low serum adiponectin is associated with high circulating oxidized low-density lipoprotein in patients with type 2 diabetes mellitus and coronary artery disease. Metabolism 2007, 56:881-886.

30. Seino $Y$, Nanjo K, Tajima N, Kadowaki T, Kashiwagi A, Araki A, Ito C, Inagaki $\mathrm{N}$, Iwamoto $Y$, Kasuga $M$, et al: The committee of japan diabetes society on the diagnostic criteria of diabetes mellitus: report of the committee on the classification and diagnostic criteria of diabetes mellitus. Diabeto Int 2010, 1:2-20

31. Miyauchi K, Kayahara N, Ishigami M, Kuwata $H$, Mori $H$, Sugiuchi $H$, Irie T, Tanaka A, Yamashita S, Yamamura T: Development of a homogeneous assay to measure remnant lipoprotein cholesterol. Clin Chem 2007, 53:2128-2135

32. Teramoto T, Sasaki J, Ueshima H, Egusa G, Kinoshita M, Shimamoto K, Daida H, Biro S, Hirobe K, Funahashi T, et al: Metabolic syndrome. J Atheroscler Thromb 2008, 15:1-5.

33. Ceriello A, Taboga C, Tonutti L, Quagliaro L, Piconi L, Bais B, Da Ros R, Motz E: Evidence for an independent and cumulative effect of postprandial hypertriglyceridemia and hyperglycemia on endothelial dysfunction and oxidative stress generation: effects of short- and long-term simvastatin treatment. Circulation 2002, 106:1211-1218.

34. Anderson RA, Evans ML, Ellis GR, Graham J, Morris K, Jackson SK, Lewis MJ, Rees A, Frenneaux MP: The relationships between post-prandial lipaemia, endothelial function and oxidative stress in healthy individuals and patients with type 2 diabetes. Atherosclerosis 2001, 154:475-483.

35. Shin HK, Kim YK, Kim KY, Lee JH, Hong KW: Remnant lipoprotein particles induce apoptosis in endothelial cells by $\mathrm{NAD}(\mathrm{P}) \mathrm{H}$ oxidase-mediated production of superoxide and cytokines via lectin-like oxidized lowdensity lipoprotein receptor-1 activation: prevention by cilostazol. Circulation 2004, 109:1022-1028.

36. Watson AD, Berliner JA, Hama SY, La Du BN, Faull KF, Fogelman AM, Navab M: Protective effect of high density lipoprotein associated paraoxonase. Inhibition of the biological activity of minimally oxidized low density lipoprotein. J Clin Invest 1995, 96:2882-2891.

37. Ridker PM, Cannon CP, Morrow D, Rifai N, Rose LM, McCabe CH, Pfeffer MA, Braunwald E: C-reactive protein levels and outcomes after statin therapy. N Engl J Med 2005, 352:20-28.

38. Morrow DA, de Lemos JA, Sabatine MS, Wiviott SD, Blazing MA, Shui A, Rifai $\mathrm{N}$, Califf RM, Braunwald E: Clinical relevance of C-reactive protein during follow-up of patients with acute coronary syndromes in the aggrastatto-zocor trial. Circulation 2006, 114:281-288

39. Tao L, Gao E, Jiao X, Yuan Y, Li S, Christopher TA, Lopez BL, Koch W, Chan L, Goldstein BJ, Ma XL: Adiponectin cardioprotection after myocardial ischemia/reperfusion involves the reduction of oxidative/nitrative stress. Circulation 2007, 115:1408-1416.

40. Li R, Wang WQ, Zhang H, Yang X, Fan Q, Christopher TA, Lopez BL, Tao L, Goldstein BJ, Gao F, Ma XL: Adiponectin improves endothelial function in hyperlipidemic rats by reducing oxidative/nitrative stress and differential regulation of eNOS/iNOS activity. Am J Physiol Endocrinol Metab 2007, 293:E1703-E1708.

41. Keaney JF Jr, Larson MG, Vasan RS, Wilson PW, Lipinska I, Corey D, Massaro JM, Sutherland P, Vita JA, Benjamin EJ: Obesity and systemic oxidative stress: clinical correlates of oxidative stress in the Framingham study. Arterioscler Thromb Vasc Biol 2003, 23:434-439.

42. Zhou G, Myers R, Li Y, Chen Y, Shen X, Fenyk-Melody J, Wu M, Ventre J, Doebber T, Fujii N, et al: Role of AMP-activated protein kinase in mechanism of metformin action. J Clin Invest 2001, 108:1167-1174.

43. Satoh N, Shimatsu A, Yamada K, Aizawa-Abe M, Suganami T, Kuzuya H, Ogawa Y: An alpha-glucosidase inhibitor, voglibose, reduces oxidative stress markers and soluble intercellular adhesion molecule 1 in obese type 2 diabetic patients. Metabolism 2006, 55:786-793.

44. Maeda N, Takahashi M, Funahashi T, Kihara S, Nishizawa H, Kishida K, Nagaretani H, Matsuda M, Komuro R, Ouchi N, et al: PPARgamma ligands increase expression and plasma concentrations of adiponectin, an adipose-derived protein. Diabetes 2001, 50:2094-2099.

45. Iwaki M, Matsuda M, Maeda N, Funahashi T, Matsuzawa Y, Makishima M, Shimomura I: Induction of adiponectin, a fat-derived antidiabetic and antiatherogenic factor, by nuclear receptors. Diabetes 2003, 52:1655-1663

46. Okuno Y, Matsuda M, Kobayashi H, Morita K, Suzuki E, Fukuhara A, Komuro $R$, Shimabukuro M, Shimomura I: Adipose expression of catalase is regulated via a novel remote PPARgamma-responsive region. Biochem Biophys Res Commun 2008, 366:698-704

47. Okuno Y, Matsuda M, Miyata Y, Fukuhara A, Komuro R, Shimabukuro M, Shimomura I: Human catalase gene is regulated by peroxisome proliferator activated receptor-gamma through a response element distinct from that of mouse. Endocr J 2010, 57:303-309. 
48. Lee YS, Kim AY, Choi JW, Kim M, Yasue S, Son HJ, Masuzaki H, Park KS, Kim JB: Dysregulation of adipose glutathione peroxidase 3 in obesity contributes to local and systemic oxidative stress. Mol Endocrinol 2008, 22:2176-2189.

49. UK Prospective Diabetes Study (UKPDS) Group: Effect of intensive bloodglucose control with metformin on complications in overweight patients with type 2 diabetes (UKPDS 34). Lancet 1998, 352:854-865.

50. Chiasson JL, Josse RG, Gomis R, Hanefeld M, Karasik A, Laakso M: Acarbose treatment and the risk of cardiovascular disease and hypertension in patients with impaired glucose tolerance: the STOP-NIDDM trial. JAMA 2003, 290:486-494.

doi:10.1186/1758-5996-5-77

Cite this article as: Matsuda et al: Impact of dyslipidemic components of metabolic syndrome, adiponectin levels, and anti-diabetes medications on malondialdehyde-modified low-density lipoprotein levels in statin-treated diabetes patients with coronary artery disease. Diabetology \& Metabolic Syndrome 2013 5:77.

\section{Submit your next manuscript to BioMed Central and take full advantage of:}

- Convenient online submission

- Thorough peer review

- No space constraints or color figure charges

- Immediate publication on acceptance

- Inclusion in PubMed, CAS, Scopus and Google Scholar

- Research which is freely available for redistribution 